\title{
A Closer eXamination of The Claims of Excellent Corrosion Resistance of Stainless Steel: TEXTBOOK MisconCEPTIONS AND MisinTERPRETATIONS
}

\author{
Aezeden O. Mohamed \\ Faculty of Engineering and Applied Science, Memorial University, St. John's, NL, Canada, A1B 3X5 \\ amohamed@mun.ca
}

\begin{abstract}
This paper examines misconceptions and misinterpretations concerning the common assertion in textbooks that stainless steels has excellent corrosion resistance due to the addition of alloying elements such as nickel (Ni), chromium (Cr), and molybdenum (Mo).

A closer look at this claim reveals underlying assumptions that lead to this imprecise statement. Corrosion experiments have been established in a course in engineering materials that expose these assumptions.

Following a discussion of the tests and their results, it is suggested that statements in textbooks that stainless steel has excellent corrosion resistance should be qualified. It is hoped that by bringing this shortcoming to the attention of engineering educators, the misconceptions and misinterpretations can be corrected.
\end{abstract}

Keywords: Corrosion resistance, misconceptions, misinterpretations, stainless steel, students, textbook.

\section{INTRODUCTION}

During the writer's years of teaching an introductory course in materials science and other materials-related engineering courses in Memorial University and University of Manitoba, curious freshmen have questioned the statement commonly found in textbooks that stainless steels has excellent corrosion resistance [1].

Such a misconception occurs particularly when teacher present courses on materials properties or on the classification of metals and their alloys such as stainless steels, such courses include materials selection, materials physics, materials chemistry, materials, manufacturing processes, and fracture of materials. These courses, one way or the other, introduce various engineering alloys suitable for corrosive environments with stainless steel alloys being the most common.

Freshmen often ask the question why, stainless steel, since it is largely steel, has such excellent corrosion resistance in comparison to pure steel. Teachers often respond that its superior corrosion properties are due to the addition of $12 \% \mathrm{Cr}$ or more, and that the addition of $\mathrm{Ni}$ and Mo will provide further resistance to corrosion in severe environments.

Students can come to the misleading conclusion that stainless steel and related alloys are the ultimate solution for any corrosion problem.

This paper's subject matter is based on the author's personal experience and observations that many textbooks used by engineering freshmen commonly classify stainless steel as having excellent corrosion resistance. To bring this misconception to students attention, the author developed simple corrosion experiments to demonstrate that under some conditions even stainless steel can suffer corrosion.

The test and typical results are presented here for the benefit of teachers (as well as researchers) and, of course, students.

\section{METHODOLOGY}

Twelve samples of aluminum (Al), steel $(\mathrm{Fe})$ and stainless steel (S.S) (36 in total) are prepared by sectioning and each sample ground and polished with 600 grit sand paper, degreased in a detergent solution, and dried. The 36 samples are evaluated for the occurrence of crevice corrosion after experiencing different levels of and different durations in corrosive environments. It is important to note that the dimensions of the test samples are not critical in the development of crevice corrosion.

The critical factor is that elastic bands placed around each sample are tightly held again the sample at its centre so that crevice corrosion can form underneath the band. Typically, tighter elastic bands promote greater localized corrosive attack.

Elastic bands was used for reproducibility of results and to simulate "real world" crevice corrosion that occurs when, for example, two strips of sheet metals are held together by a nut and bolt or a screw. Crevice corrosion developed underneath washers often remains hidden and 
is not discovered in its early stages. This form of simple but undetected crevice corrosion can lead to catastrophic disaster (e.g. Aloha Airlines Boeing 737 in1988). The severity of the crevice environment increases over time, such that the local attack rate can accelerate with time.

In the tests, the elastic bands are used to suspend the sample in the beaker containing the solutions. Two samples of each material are suspended in each beaker. Three solution concentrations of $\mathrm{NaCl}$ and $\mathrm{FeCl} 3$ were prepared $-0.1 \%, 1 \%$ and $10 \%$. One sample of the two in each beaker was removed after 3 days and the other sample after 7 days (See Fig. 1).

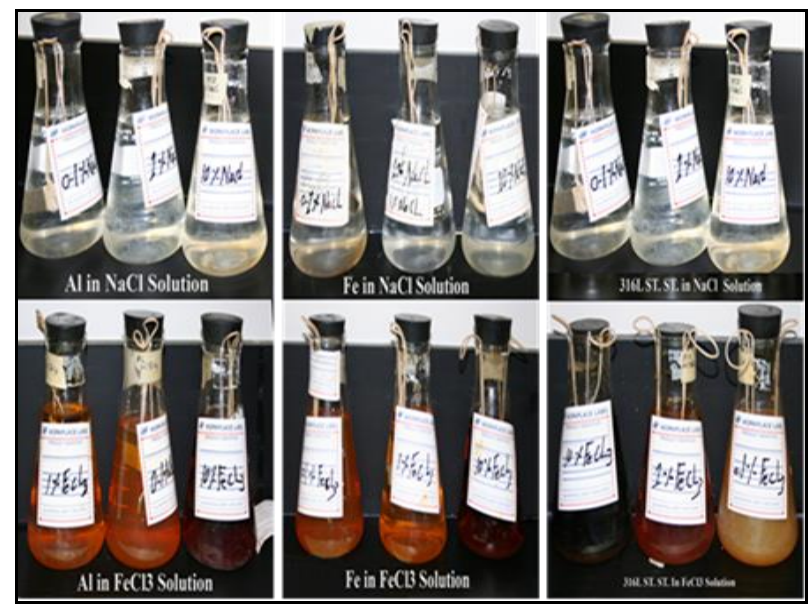

Fig. 1. Samples immersed in $\mathrm{NaCl}$ solution (first row), and in $\mathrm{FeCl}_{3}$ solutions (second row).

For consistency of description, students were required to record the level of crevice corrosion in one of the following four categories: none observed; slight; moderate; severe. Also, $\mathrm{pH}$ values were measured and recorded before samples were immersed. For the $\mathrm{NaCl}$ solutions with concentrations of $0.1 \%, 1 \%$ and $10 \%$ the $\mathrm{pH}$ values were 9, 9.2, and 9.7, respectively, and for $\mathrm{FeCl}_{3}$ solutions with concentrations of $0.1 \%, 1 \%$ and $10 \%$ the respective pH's were $2.9,2.8$ and 2.0. On Day 03, one sample was extracted from each beaker and the elastic bands carefully removed. Samples were then evaluated for the degree of crevice corrosion (if any) beneath each elastic band.

This procedure was repeated for the second set of samples immersed until Day 07.

\section{RESULTS AND DISCUSSIONS}

Students found that the $\mathrm{NaCl}$ solutions in three different concentrations did not produce any visible effects on $\mathrm{Al}, \mathrm{Fe}$, and S.S, samples even when the exposure time increased to 7 days (see Fig. 2 and Fig. 3), i.e. no crevice corrosion was observed.

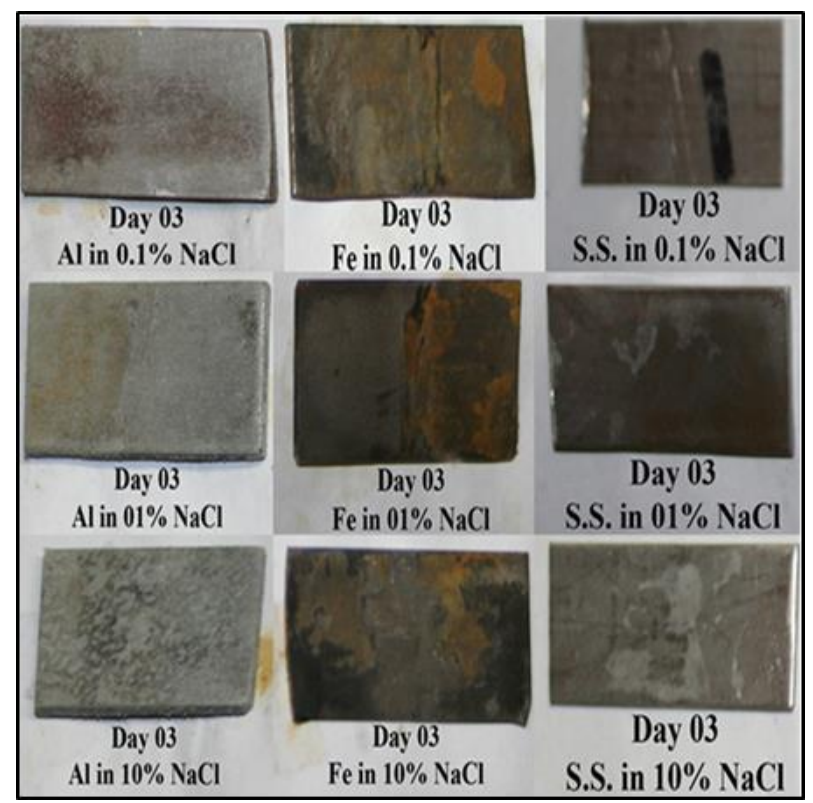

Fig. 2. No crevice observed in Al, Fe, S.S samples immersed in $\mathrm{NaCl}$ solution on Day 03.

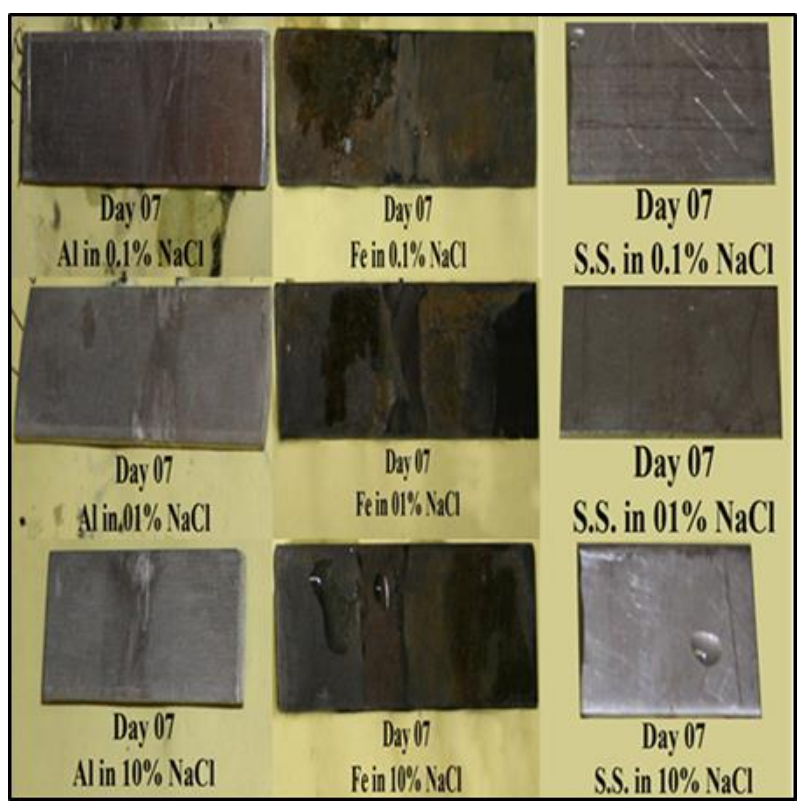

Fig. 3. No crevice corrosion observed for $\mathrm{Al}, \mathrm{Fe}, \mathrm{S} . \mathrm{S}$ samples in $\mathrm{NaCl}$ solutions on Day 07.

For the three $\mathrm{FeCl}_{3}$ solutions no crevice corrosion was observed on $\mathrm{Al}$ after 3 days, whereas for higher concentrations of $1 \%$ and $10 \% \mathrm{FeCl}_{3}$ slight and moderate visible corrosion was observed on $\mathrm{Fe}$ samples. For stainless steel (S.S) moderate and severe corrosion occurred with concentrations of $1 \%$ and $10 \% \mathrm{FeCl}_{3}$ (see Fig. 4). 


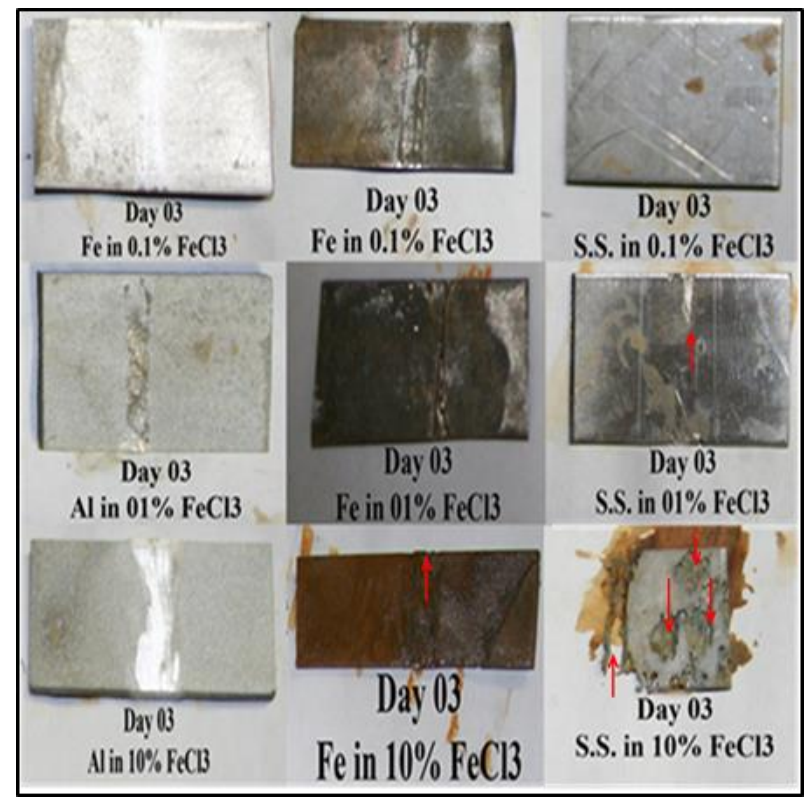

Fig. 4. Moderate crevice for Fe, severe crevice for S.S sample in $\mathrm{FeCl}_{3}$ solution on Day 03.

It can be clearly seen that as solution concentration increases so does the severity of crevice corrosion. Furthermore, the three materials exposed for 7 days in $\mathrm{FeCl}_{3}$ solutions showed different levels of corrosion. In $\mathrm{Al}$ samples, no crevice corrosion was observed (Fig. 5), but the Fe samples had evidence of slight to moderate corrosion at $1 \%$ and $10 \%$ respectively. The S.S samples exhibited crevice corrosion even at the lowest concentration of $0.1 \%$, and moderate to severe crevice corrosion at $1 \%$ and $10 \%$ respectively (Fig. 5).

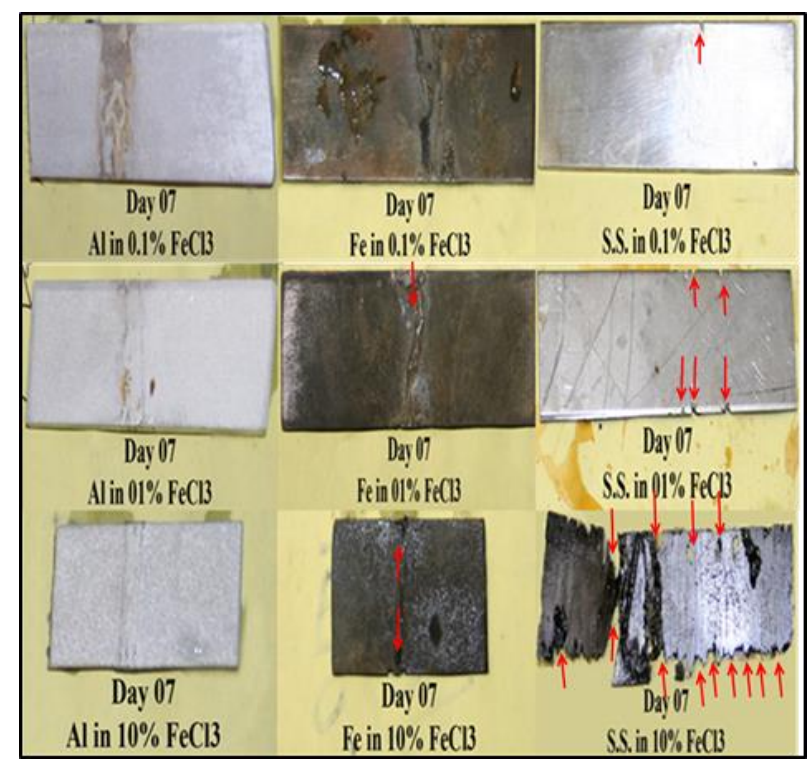

Fig. 5. Moderate crevice corrosion observed in Fe and severe in S.S.in $\mathrm{FeCl}_{3}$ solution on Day 07.
Al samples immersed in $\mathrm{NaCl}$ solutions and those immersed in $\mathrm{FeCl}_{3}$ solutions exhibited no crevice corrosion in any of the three concentrations $(0.1 \%, 1 \%$ and $10 \% \mathrm{NaCl}$ ) after 3 and after 7 days of exposure. The Fe samples experienced moderate crevice corrosion only with the highest $\mathrm{FeCl}_{3}$ solution concentration $\left(10 \% \mathrm{FeCl}_{3}\right)$. S.S in $10 \% \mathrm{FeCl}_{3}$ solution exhibited the most severe crevice corrosion of any of the materials. Severe crevice corrosion was noted from Day 03 and many of these samples were dissolved and depleted after 7 days.

After students have evaluated their data they can be asked, "What would happen if S.S samples were immersed in $\mathrm{FeCl}_{3}$ solution for a month? Why did additions of alloying elements $\mathrm{Ni}, \mathrm{Cr}$, and $\mathrm{Mo}$ not prevent corrosion as presented in textbook? Why did the Fe samples exhibit better resistance to corrosion than S.S?"

The test results expose some misconceptions that students can have concerning stainless steels. Teachers should address these misconceptions where the course textbook has not made some qualifications on the generally excellent corrosion resistance of S.S. in many environments.

Students should be taught that under certain environments stainless steel has the potential for greater crevice corrosion than steel itself.

Another area requiring explanation for students is the effect of the addition of alloying elements in superalloys and the corrosion resistance relative to stainless steel. It is known that the addition of Mo to superalloy $(\mathrm{Ni}-\mathrm{Cr})$ will further increase resistance to corrosion as compared to the Mo free alloy. However, the addition of Mo to stainless steels does not increase resistance to corrosion and the Mo-bearing stainless steel remains susceptible to corrosion $[2,3]$.

Why do additions of Mo to superalloy (Ni-Cr) increase resistance to corrosion, whereas additions of Mo to stainless steels do not remain a puzzle that is not yet understand? Students should be aware of this fact so as not to have the misconception that Mo additions always increase corrosion resistance.

\section{STUDENTS REACTIONS}

For students, the experimental work described in this paper proved very effective in qualifying and drawing attention to the general statement commonly found in textbooks that stainless steel has excellent corrosion resistance.

Some typical student comments regarding the corrosion experiment are as follows. (1) Prior to the completion of the experiment students expected and believed steel samples would suffer most crevice corrosion and stainless steel samples would be the most 
resistant. (2) The corrosion experiment is very simple in principle and set up yet critical and interesting, but more time was needed for observation to witness how stainless steel samples will dissolve in $10 \% \mathrm{FeCl} 3$ solution. (3) Stainless steel showed good corrosion resistance in the sodium chloride solution. (4) The experiment provided an excellent example of the corrosion process. (5) Learning from observing is more convincing that book learning.

In general, the students' responses to the lab experiment were overwhelmingly positive. Though the work load is small, the lab is effective because it involves active learning and allows students to use their powers of observations to validate for themselves the misinformation commonly found in textbooks that stainless steel has excellent corrosion resistance. Students' positive comments indicate that the lab experiment was general well received and of value.

\section{CONCLUSIONS AND SUGGESTIONS}

The author recommends that textbooks in which qualifications about the excellent corrosion resistance of stainless steel alloys have not been made should be corrected so as to avoid misunderstanding by engineering educators and the general public.

\section{Acknowledgements}

The author gratefully acknowledges the assistance of Dr. Greg Naterer, Dean of Engineering and Applied Science at Memorial University, and financial support from the Natural Sciences and Engineering Research Council of Canada (NSERC).

\section{References}

[1] Callister, W. D. G. David Rethwisch, Classification of Ferrous Metal Alloys. Materials Science and Engineering: An Introduction, $8^{\text {th }}$ Edition, 2009.

[2] Jack R. Cahoon and C. T. F. Cheung, The Susceptibility of Metallic Surgical Implant materials to Crevice Corrosion, Canadian Metallurgical Quarterly, Vol. 21, Issue 3, pp. 289, 1982.

[3] Aezeden Mohamed, Jack Cahoon, and William Caley, Anodic Polarization Behavior of Nickel-Based Alloys in Neutral and Very Acidic Solutions, Corrosion Science and Engineering, Vol. 15, Issue 37, pp. 1, 2012. 